\title{
Hyperosmolar hyperglycemic state as the first manifestation of type 1 diabetes mellitus in an adolescent male: a case report
}

\author{
Sang Hoon Chun, \\ Hae Sang Lee, \\ Jin Soon Hwang
}

Department of Pediatrics, Ajou University Hospital, Ajou University School of Medicine, Suwon, Korea
Received: 14 December, 2020

Revised: 31 March, 2021

Accepted: 30 June, 2021

Address for correspondence:

Hae Sang Lee

Department of Pediatrics, Ajou University School of Medicine, San 5, Wonchon-dong, Yeongtong-gu, Suwon 16499, Korea

Email: seaon98@ajou.ac.kr

https://orcid.org/0000-0002-96844042

\begin{abstract}
A hyperosmolar hyperglycemic state (HHS) is a life-threatening complication rarely seen in children and adolescents with type 1 diabetes mellitus (T1DM). However, early diagnosis and proper treatment are vital to reduce the high morbidity and mortality rates associated with HHS. We describe a male patient who presented with polydipsia, polyuria, and a drowsy mental status. His initial biochemistry results demonstrated severe hyperglycemia $(1,456 \mathrm{mg} / \mathrm{dL})$, hyperosmolarity of $359 \mathrm{mOsm} / \mathrm{kg}$ (effective osmolarity, $323 \mathrm{mOsm} / \mathrm{kg}$ ), and mild acidosis (venous $\mathrm{pH}, 7.327)$. The patient was diagnosed with HHS and T1DM based on the presence of hyperosmolarity, hyperglycemia, and positivity for antiglutamic acid antibodies. Intensive intravenous fluid and regular insulin $(0.025 \mathrm{units} / \mathrm{kg} / \mathrm{hr})$ were administered. After hydration and insulin treatment, the patient's mental status and serum glucose and sodium levels improved, and no neurological complications were observed. In summary, most cases of HHS are observed in adult patients with type 2 diabetes. However, occurrences in children and adolescents with T1DM have also been reported. Therefore, HHS should be considered in the differential diagnosis of hyperglycemic emergencies.
\end{abstract}

Keywords: Hyperosmolar hyperglycemic state, Type 1 diabetes mellitus, Insulin

\section{Highlights}

- Early diagnosis and appropriate treatment are important for HHS management. Pediatric endocrinologists should consider HHS as differential diagnosis in hyperglycemic crisis in children and adolescents.

\section{Introduction}

Acute hyperglycemic crises, including a hyperosmolar hyperglycemic state (HHS) and diabetic ketoacidosis (DKA), are severe metabolic complications occurring in patients with diabetes. ${ }^{1)}$ HHS is characterized by severe hyperglycemia and hyperosmolarity without evidence of severe ketosis or acidosis. Due to the similarity of clinical features between DKA and HHS, including fatigue, malaise, polyuria, nausea, and changes in consciousness, distinguishing between these 2 conditions based on patient medical history alone is challenging. However, their diagnostic criteria differ from one another. ${ }^{2)}$ The biochemical criteria for the diagnosis of DKA (Table 1) include hyperglycemia (blood glucose $>200$ $\mathrm{mg} / \mathrm{dL}$ ), a venous $\mathrm{pH}$ of $<7.3$, or a serum bicarbonate concentration of $<15 \mathrm{mmol} / \mathrm{L}$ with ketonemia or ketonuria. The criteria for HHS include hyperglycemia (blood glucose $>600$ $\mathrm{mg} / \mathrm{dL}$ ), an arterial $\mathrm{pH}$ of $>7.30$, a venous $\mathrm{pH}$ of $>7.25$, a serum bicarbonate concentration of $>15 \mathrm{mmol} / \mathrm{L}$, small ketonuria, small (or absent) ketonemia, effective serum osmolarity of 
$>320 \mathrm{mOsm} / \mathrm{kg}$, obtundation, combativeness, or seizures (in approximately $50 \%$ of cases).

HHS is mainly diagnosed in elderly patients with type 2 diabetes mellitus (T2DM) and has a higher mortality rate (10\%$50 \%$ ) compared to that for DKA. ${ }^{2)}$ Although HHS is rarely the first presentation of type 1 diabetes mellitus (T1DM), there have been several reports of its occurrence in T1DM. ${ }^{3-6)}$ However, HHS rarely occurs in children and adolescents with T1DM, and early diagnosis and proper treatment are important because of its high mortality rate. ${ }^{7)}$ Here, we report the case of a 17 -year-old adolescent male patient with T1DM who presented with HHS. Furthermore, we briefly reviewed the most recent pediatric cases of HHS in T1DM patients.

\section{Case report}

A 17-year-old boy presented to the Emergency Department with severe polydipsia and lethargy. He had a 7-day history of anorexia and a 3-day history of polyuria and polydipsia. His weight had decreased from $55 \mathrm{~kg}$ to $44 \mathrm{~kg}$ in the past month. He was previously healthy and had no past admissions or serious illnesses. There was no personal or family history of endocrine diseases, including diabetes mellitus.

Table 1. Differential diagnosis and treatment of DKA and HHS

\begin{tabular}{lcc}
\hline Variable & DKA & HHS \\
\hline Blood glucose $(\mathrm{mg} / \mathrm{dL})$ & $>200$ & $>600$ \\
Venous $\mathrm{pH}$ & $<7.3$ & $>7.25$ \\
Serum $\mathrm{HCO}_{3}^{-}(\mathrm{mmol} / \mathrm{L})$ & $<15$ & $>15$ \\
$\begin{array}{l}\text { Effective serum osmolarity } \\
\quad \text { (mOsm/kg) }\end{array}$ & Variable & $>320$ \\
Ketonuria & $(+)$ & Small or absent \\
Ketonemia & $(+)$ & Small or absent \\
Estimated fluid deficit (\%) & 6 & $12-15$ \\
Fluid deficit correction (hr) & 24 & $>48$ \\
Initial insulin therapy & 0.1 unit $/ \mathrm{kg} / \mathrm{hr}$ & $0.025-0.05 \mathrm{unit} / \mathrm{kg} / \mathrm{hr}$ \\
\hline DKA, diabetic ketoacidosis;
\end{tabular}

DKA, diabetic ketoacidosis; HHS, hyperosmolar hyperglycemic state.

Adapted from Wolfsdorf et al. Pediatr Diabetes 2018;19 Suppl 27:155-77.11)
On admission, the patient's height was $173.2 \mathrm{~cm}$, which was a 0.15 standard deviation score (SDS) based on the Korean normal reference. His weight was $43.6 \mathrm{~kg}(-3.13$ SDS) and his body mass index was $14.57 \mathrm{~kg} / \mathrm{m}^{2}(-3.43$ SDS $\left.){ }^{8}\right)$ His temperature was $37.0^{\circ} \mathrm{C}$, heart rate was $96 \mathrm{bpm}$, respiratory rate was 22 breaths/min, and blood pressure was 118/70 $\mathrm{mmHg}$, respectively. A physical examination revealed mild drowsiness (Glasgow Coma Scale score, 13 points) but intact sensation and normal motor strength.

Initial laboratory data on admission revealed a serum glucose level of $1,456 \mathrm{mg} / \mathrm{dL}$, serum osmolarity of $359 \mathrm{mOsm} / \mathrm{kg}$ (effective osmolarity, $323 \mathrm{mOsm} / \mathrm{kg}$ ), serum urea nitrogen level of $67.9 \mathrm{mg} / \mathrm{dL}$, and creatinine level of $2.93 \mathrm{mg} / \mathrm{dL}$. In addition, his initial serum sodium level was $143 \mathrm{mmol} / \mathrm{L}$, with a corrected sodium level of $156.6 \mathrm{mmol} / \mathrm{L}$ (Table 2). Venous blood gas analysis revealed a $\mathrm{pH}$ of 7.327 , base excess of -7.65 , and serum bicarbonate level of $16.4 \mathrm{mmol} / \mathrm{L}$. Urine analysis revealed a glucose level of $3+$, with a $1+$ result for ketones.

The patient was diagnosed with HHS due to T1DM and was admitted to the intensive care unit. He was managed with cautious fluid replacement for an estimated $20 \%$ deficit over 72 hours with a $500-\mathrm{mL} 0.9 \%$ normal saline bolus for 1 hour to correct his circulating volume. After normal saline loading, we began intravenous insulin infusion (regular insulin, $0.1 \mathrm{U} /$ $\mathrm{kg} / \mathrm{hr}$ ), which was reduced to $0.025 \mathrm{U} / \mathrm{kg} / \mathrm{hr}$ within 4 hours after confirmation of the diagnosis of HHS. The recommended dosage of continuous insulin in HHS is $0.025-0.05$ units/ $\mathrm{kg} / \mathrm{hr}$ compared to that of $0.1 \mathrm{unit} / \mathrm{kg} / \mathrm{hr}$ used in DKA. In addition, since our patient had neurological symptoms, including headache and drowsiness, mannitol was administered intravenously owing to the possibility of cerebral edema. After 34 hours of fluid administration, the patient's mental status became alert and his headache had subsided. Moreover, his serum glucose and corrected sodium levels had gradually improved (Fig. 1).

Finally, laboratory results confirmed T1DM. The patient's glycated hemoglobin level was $10.2 \%$ (reference, $<5.6 \%$ ) and his serum C-peptide level was $0.11 \mathrm{ng} / \mathrm{mL}$ (reference, $1.06-3.53 \mathrm{ng} /$ $\mathrm{mL}$ ). Additionally, his antiglutamic acid antibody level was 8.09 $\mathrm{U} / \mathrm{mL}$ (reference, $4.9 \mathrm{U} / \mathrm{mL}$ ), his insulin antibody level was 5.6\%

Table 2. Laboratory results of the case

\begin{tabular}{|c|c|c|c|c|c|c|}
\hline Variable & References & Initial & 8 Hours & 20 Hours & 40 Hours & 72 Hours \\
\hline $\mathrm{pH}$ & $7.35-7.45$ & 7.327 & 7.360 & 7.359 & 7.372 & 7.503 \\
\hline $\mathrm{PCO}_{2}(\mathrm{mmHg})$ & $35.0-45.0$ & 31.0 & 39.5 & 35.6 & 35.9 & 33.0 \\
\hline $\mathrm{HCO}_{3}^{-}(\mathrm{mmol} / \mathrm{L})$ & $23.0-29.0$ & 16.4 & 21.8 & 19.6 & 20.4 & 25.3 \\
\hline Base excess (mM) & -3.0 to 3.0 & -7.6 & -3.3 & -4.8 & -4.1 & 2.6 \\
\hline Corrected $\mathrm{Na}^{+}(\mathrm{mEq} / \mathrm{L})$ & $135-145$ & 161 & 160 & 165 & 157 & 149 \\
\hline Serum K+ $(m E q / L)$ & $3.5-5.5$ & 5.7 & 4.2 & 4.3 & 5.0 & 4.8 \\
\hline Serum $\mathrm{Cl}^{-}(\mathrm{mEq} / \mathrm{L})$ & 98-107 & 94 & 113 & 127 & 124 & 116 \\
\hline Serum glucose (mg/dL) & 74-106 & 1456 & 583 & 111 & 187 & 170 \\
\hline Serum BUN (mg/dL) & $5.0-18.0$ & 67.9 & 59.8 & 55.8 & 41.1 & 29.7 \\
\hline Serum creatinine (mg/dL) & $0.40-0.60$ & 2.93 & 2.81 & 2.4 & 1.76 & 1.17 \\
\hline Plasma osmolarity (mOsm/L) & $275-295$ & 359 & - & 364 & 349 & 363 \\
\hline
\end{tabular}

BUN, blood urea nitrogen. 


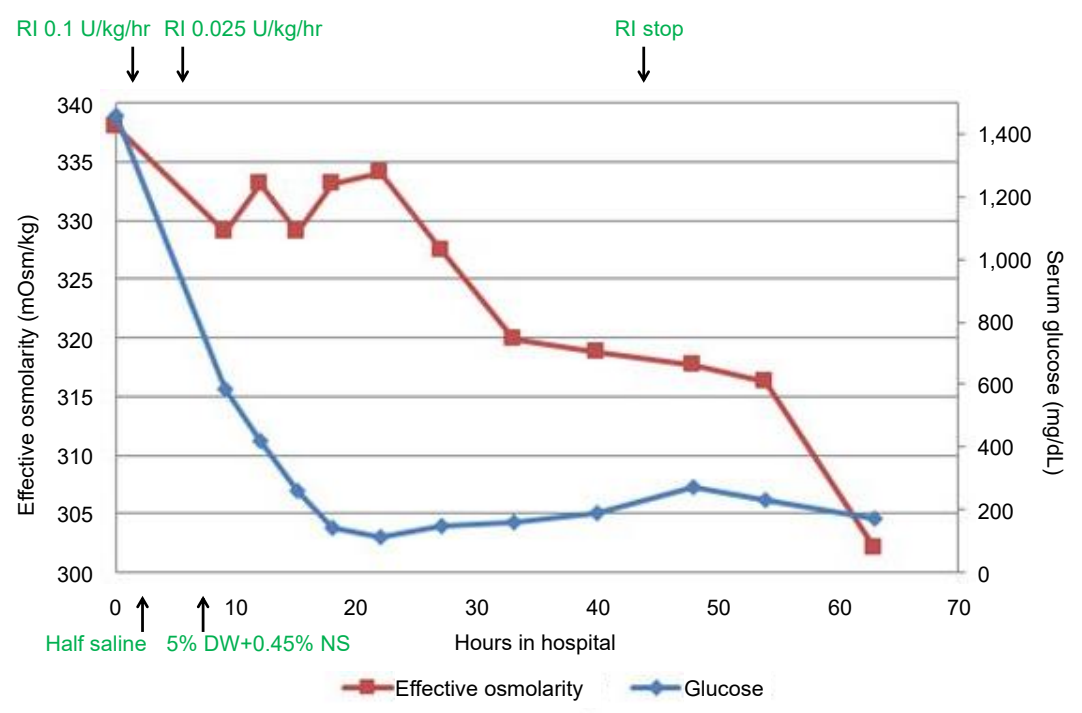

Fig. 1. Time course of laboratory findings from hospital admission to 60 hours. DW, dextrose water; NS, normal saline.

(reference, 7.0\%), and he was negative for islet cell antibodies. His 24 -hr urine C-peptide rate was $0.42 \mu \mathrm{g} /$ day (reference, $17.2-181.0 \mathrm{mg} /$ day). The patient and his family members were educated on intensive insulin therapy and carbohydrate counting. The patient's blood glucose levels were controlled with intensive insulin therapy (regular insulin, $0.1 \mathrm{U} / \mathrm{kg} / \mathrm{hr}$ ) and carbohydrate counting $(0.8 \mathrm{U} / \mathrm{kg} /$ day). He was discharged without any neurological complications 6 days after admission.

\section{Discussion}

HHS is a life-threatening endocrine emergency that most commonly affects adults with T2DM.) The incidence of HHS in pediatric patients is unclear but is estimated to account for $<1 \%$ of hospital admissions in patients with diabetes. ${ }^{11}$ Rosenbloom ${ }^{9}$ reviewed 97 published cases of HHS in children and adolescents from 1966-2008, finding that 33 had been diagnosed with T1DM. In addition, Agrawal et al. ${ }^{10)}$ reported HHS at first presentation in 2 pediatric patients with T1DM among 411 hyperglycemic emergencies. Very rarely, cases of mixed HHS and DKA in T1DM patients have been reported. For HHS, the rate of fluid and electrolyte administration exceeds that required for the typical case of DKA to maintain an adequate circulatory volume. $^{10)}$

Hyperglycemia in patients with DKA leads to osmotic diuresis and electrolyte imbalance due to increased glucose production by the liver and kidneys and peripheral glucose utilization disorders. Ketonemia and metabolic acidosis result from increased lipolysis and increased ketoacid production. ${ }^{1)}$ Both DKA and HHS result from a deficiency of circulating insulin and increased levels of the counter-regulatory hormones catecholamines, glucagon, cortisol, and growth hormone. HHS is characterized by extreme elevations in serum glucose concentrations and hyperosmolarity without significant ketosis. Higher hepatic and circulating insulin concentrations with relatively lower glucagon are present in patients with HHS compared to those with DKA. The higher circulating insulin/ glucagon ratio in patients with HHS prevents ketogenesis and the development of ketoacidosis. ${ }^{11)}$

It is important to understand the differences between the treatments available for DKA and HHS. Prompt diagnosis and proper treatment are essential to prevent serious complications of HHS. The treatment goal in HHS is to expand intravascular and extravascular volumes and restore normal kidney perfusion. The rate of fluid treatment in HHS is faster than that recommended for DKA. In addition, isotonic fluid is more effective in maintaining the circulating volume. Unlike DKA, hypernatremia can occur in HHS patients. Mortality is mostly associated with a failure to reduce the corrected serum sodium concentration, which can be an indication for dialysis in some cases. The corrected sodium concentration was frequently measured in this case to monitor its gradual decrease. There are no data that suggest the appropriate speed for adjusting serum sodium concentration; however, a dose of $0.5 \mathrm{mmol} / \mathrm{L} / \mathrm{hr}$ is recommended for hypernatremic dehydration. ${ }^{11)}$ In our case, hypernatremia was detected during initial laboratory testing. If hypernatremia occurs with severe hyperglycemia, clinicians should consider the possibility of HHS and more attention should be paid to fluid treatment.

Continuous insulin therapy may not be required for the treatment of HHS; however, insulin therapy can be considered when serum glucose levels do not decline adequately with fluid hydration alone or in children with significant ketosis and acidosis. The recommended dosage of continuous insulin in HHS is $0.025-0.05$ units $/ \mathrm{kg} / \mathrm{hr}$ compared to that of 0.1 units/ $\mathrm{kg} / \mathrm{hr}$ generally used in DKA; a dose reduction should be 
considered if the serum glucose concentration decreases below $50-75 \mathrm{mg} / \mathrm{dL} / \mathrm{hr}^{2)}$

The reported mortality rate of HHS is $50 \%-60 \%$, with a recent cohort study reporting a 30-day mortality rate of $16 \%{ }^{12)}$ Therefore, clinicians should consider a diagnosis of HHS in children and adolescents experiencing hyperglycemic emergencies. In addition, cautious therapy, such as hydration and insulin supplementation, is critical for reducing morbidity and mortality rates in HHS.

In conclusion, we reported a case of HHS with hypernatremia in T1DM in an adolescent patient who was initially suspected to have DKA. Our patient was diagnosed with T1DM that evolved into HHS with hypernatremia. We initially considered DKA instead of HHS, given its prevalence in pediatric patients, but our patient's diagnosis was later confirmed to be HHS based on his serum glucose level, hyperosmolarity, and hypernatremia. The occurrence of HHS in T1DM is very rare; however, the morbidity and mortality rates due to HHS are approximately 10 times higher than those seen with DKA. ${ }^{13)}$

\section{Ethical statement}

Our study adhered to the ethical guidelines for medical and health research involving human subjects. Consent for publication was obtained from the patient and patient's parents for the preparation and publication of this report.

\section{Notes}

Conflicts of interest: No potential conflict of interest relevant to this article was reported.

Funding: This study received no specific grant from any funding agency in the public, commercial, or not-for-profit sectors.

Acknowledgments: The authors wish to thank the patient and his parents for their kind collaboration and their contribution to this report.

Author contribution: Conceptualization: HSL; Data curation: SHC, HSL, JSH; Methodology: JSH; Visualization: SHC; Writing - original draft: SHC; Writing - review \& editing: HSL, JSH

\section{ORCID}

Sang Hoon Chun: 0000-0002-7990-455X

Hae Sang Lee: 0000-0002-9684-4042

Jin Soon Hwang: 0000-0002-2666-3801

\section{References}

1. Umpierrez G, Korytkowski M. Diabetic emergencies ketoacidosis, hyperglycaemic hyperosmolar state and hypoglycaemia. Nat Rev Endocrinol 2016;12:222-32.

2. Dhatariya KK, Vellanki P. Treatment of diabetic ketoacidosis (DKA)/hyperglycemic hyperosmolar state (HHS): novel advances in the management of hyperglycemic crises (UK versus USA). Curr Diab Rep 2017; 17:33.

3. Watanabe S, Kido J, Ogata M, Nakamura K, Mizukami T. Hyperglycemic hyperosmolar state in an adolescent with type 1 diabetes mellitus. Endocrinol Diabetes Metab Case Rep 2019;2019:18-0131.

4. Cho YM, Park BS, Kang MJ. A case report of hyperosmolar hyperglycemic state in a 7-year-old child: an unusual presentation of first appearance of type 1 diabetes mellitus. Medicine (Baltimore) 2017;96:e7369.

5. Alharfi IM, Singh R, Clarson C, Foster JR. Hyperosmolar hyperglycemic state without ketosis in a toddler with type 1 diabetes. Pediatr Emerg Care 2014;30:485-7.

6. Kershaw MJ, Newton T, Barrett TG, Berry K, Kirk J. Childhood diabetes presenting with hyperosmolar dehydration but without ketoacidosis: a report of three cases. Diabet Med 2005;22:645-7.

7. Pasquel FJ, Umpierrez GE. Hyperosmolar hyperglycemic state: a historic review of the clinical presentation, diagnosis, and treatment. Diabetes Care 2014;37:3124-31.

8. Kim JH, Yun S, Hwang SS, Shim JO, Chae HW, Lee YJ, et al. The 2017 Korean National Growth Charts for children and adolescents: development, improvement, and prospects. Korean J Pediatr 2018;61:135-49.

9. Rosenbloom AL. Hyperglycemic hyperosmolar state: an emerging pediatric problem. J Pediatr 2010;156:180-4.

10. Agrawal S, Baird GL, Quintos JB, Reinert SE, Gopalakrishnan G, Boney CM, et al. Pediatric diabetic ketoacidosis with hyperosmolarity: clinical characteristics and outcomes. Endocr Pract 2018;24:726-32.

11. Wolfsdorf JI, Glaser N, Agus M, Fritsch M, Hanas R, Rewers A, et al. ISPAD clinical practice consensus guidelines 2018: diabetic ketoacidosis and the hyperglycemic hyperosmolar state. Pediatr Diabetes 2018;19 Suppl 27:155-77.

12. Fadini GP, de Kreutzenberg SV, Rigato M, Brocco S, Marchesan M, Tiengo A, et al. Characteristics and outcomes of the hyperglycemic hyperosmolar non-ketotic syndrome in a cohort of 51 consecutive cases at a single center. Diabetes Res Clin Pract 2011;94:172-9.

13. Zeitler P, Haqq A, Rosenbloom A, Glaser N. Hyperglycemic hyperosmolar syndrome in children: pathophysiological considerations and suggested guidelines for treatment. J Pediatr 2011;158:9-14, 14.e1-2. 